\title{
Analysis of vertical marginal discrepancy in feldspathic porcelain crowns manufactured with different CAD/CAM systems: Closed and open
}

\author{
Fabio Kricheldorf ${ }^{1}$, Cleuber Rodrigo de Souza Bueno ${ }^{1}$, Wilson da Silva Amaral ${ }^{1}$, \\ Joel Ferreira Santiago Junior ${ }^{1}$, Hugo Nary Filho ${ }^{1}$
}

Correspondence: Dr. Hugo Nary Filho, Email: hugonary@institutohnary.com.br
${ }^{1}$ Department of Health Sciences, University of Sacred Heart (USC), Bauru, Brazil

\section{ABSTRACT}

Objective: The objective of this study is to compare the marginal adaptation of feldspathic porcelain crowns using two computer-aided design/computer-aided manufacturing systems, one of them is open and the other is closed. Materials and Methods: Twenty identical titanium abutments were divided into two groups: open system (OS), where ceramic crowns were created using varied equipment and software, and closed system (CS), where ceramic crowns were created using the CEREC system. Through optical microscopy analysis, we assess the marginal adaptation of the prosthetic interfaces. The data were subjected to the distribution of normality and variance. The $t$-test was used for the analysis of the comparison factor between the groups, and the one-way ANOVA was used to compare the variance of crown analysis regions within the group. A significance level of 5\% was considered for the analyses. Results: There was a significant difference between the systems $(P=0.007)$, with the CS group having the higher mean $(23.75 \mu \mathrm{m} \pm 3.05)$ of marginal discrepancy when compared to the open group $(17.94 \mu \mathrm{m} \pm 4.77)$. Furthermore, there were no differences in marginal discrepancy between the different points between the groups $(P \geq 0.05)$. Conclusions: The studied groups presented results within the requirements set out in the literature. However, the OS used presented better results in marginal adaptation.

Key words: Computer-aided design, dental prosthesis, implant supported, dental marginal adaptation, dental crown, implant rehabilitation

\section{INTRODUCTION}

The combination of technological advances and software enabled the emergence of new processes in restorative dentistry aimed at improving prosthetic rehabilitations by adding quality, standardization, and productivity. ${ }^{[1]}$ For that reason, computer-aided design (CAD) and computer-aided manufacturing (CAM) are currently a reality in dentistry and present promising results. ${ }^{[2]}$

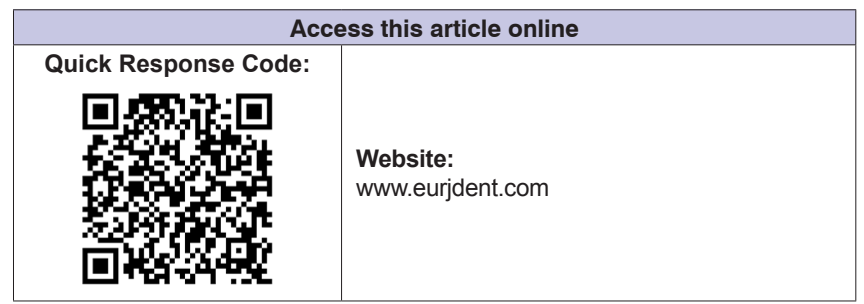

Among the crucial processes for the success of long-term rehabilitations, marginal adaptation is included for being connected with the decrease in biological and mechanical complications of the prosthesis. Given its importance, it is the most widely used in vitro analysis in literature. ${ }^{[3]}$

This is an open access article distributed under the terms of the Creative Commons Attribution-NonCommercial-ShareAlike 3.0 License, which allows others to remix, tweak, and build upon the work non-commercially, as long as the author is credited and the new creations are licensed under the identical terms.

For reprints contact: reprints@medknow.com

How to cite this article: Kricheldorf F, Bueno CR, Amaral WD,
Junior JF, Filho HN. Analysis of vertical marginal discrepancy in
feldspathic porcelain crowns manufactured with different computer-aided
design/computer-aided manufacturing systems: Closed and open. Eur J
Dent 2018;12:123-8.
DOI: $10.4103 /$ ejd.ejd_368_17


Accordingly, ceramic crowns manufactured with CAD/CAM technology are reaching lower levels of marginal discrepancy when compared with usual manufacturing processes. ${ }^{[4]}$ Regarding CAD/CAM systems, several studies are being carried out comparing levels of marginal adaptation with closed systems (CSs), i.e., systems that approach the entire manufacturing process using equipment and software of the same company. ${ }^{[5-7]}$

Nevertheless, studies comparing open systems (OSs) and CAD/CAM systems that use software and equipment from varied companies are not usual. Neither are usual studies that compare OSs with CSs, which could present differences in the manufacturing and adaptation of ceramic crowns.

The aim of this study, therefore, is to compare the level of marginal adaptation of feldspathic porcelain crowns using two different CAD/CAM systems, an OS and a CS (CEREC). The null hypothesis is that there is no difference in the marginal adaptation of feldspathic porcelain crowns using these different CAD/CAM systems.

\section{MATERIALS AND METHODS}

\section{Construction of the specimens}

The external hexagon implant with regular platform of the Original Bonelike (OBL; Rio Claro, São Paulo, Brazil) company was scanned using the Optimet ds6000 (Optimet, Jerusalem, Israel) scanner with instructions and Scan Body recommended by manufacturers. For the standardization of the crowns, the closure of a mandibular right first molar ${ }^{[8]}$ and the scanning of its surface were carried out. Next, using the Exocad software (Dentalcad; Darmstadt, Germany), an intermediate for cemented prosthesis was designed with preestablished measurements as follows: $10 \mathrm{~mm}$ (vestibular-lingual), $12 \mathrm{~mm}$ (mesial-distal), and $8 \mathrm{~mm}$ (height), with $1.2 \mathrm{~mm}$ chamfer finish line depth and anatomical reduction of $1.5 \mathrm{~mm}$ [Figure 1]. Using this model, 20 titanium specimens were milled using the machine miling DM5 (Tecnodrill, Novo Hamburgo, Rio Grande do Sul, Brazil).

\section{Study groups}

CS, $n=10$ group: In this group, the scanning of the metal specimens was carried out using the CEREC Scanner 3D Bluecam (Sirona Dental Systems $\mathrm{GmbH}$, Bensheim, Germany) for the acquisition of the images. Furthermore, a procedure of blasting a titanium dioxide film was carried out always by the same operator at a standardized distance of $3 \mathrm{~cm}$ for $5 \mathrm{~s}$ in oscillatory movements in the following directions: vestibular to lingual and mesial to distal. All crown and cervical finish line designs were conducted by the same operator, an experienced user of the software CEREC SW 4.2.4 (Sirona Dental Systems $\mathrm{GmbH}$, Bensheim, Germany). The final design was sent to the milling unit inLab MC XL CEREC (Sirona Dental Systems GmbH, Bensheim, Germany) that was used for the processing and machining of all crowns, using CEREC Blocks (Sirona Dental Systems GmbH, Bensheim, Germany).

OS, $n=10$ : the titanium dioxide blasting procedure was carried out with the same methodology used in the CS group. The scanning of the metallic pillars was carried out with the equipment Optimet Scanner DS6000 (Optimet, Jerusalem, Israel). All crown and cervical finish line designs were conducted by the same operator, an experienced user of the software CAD: Exocad (Dentalcad, Darmstadt, Germany). The final design was sent to the milling unit DM5 (Tecnodrill, Nova Hamburgo, Rio Grande do Sul, Brazil) that was used for the processing and machining of all crowns, using CEREC Blocks (Sirona Dental Systems GmbH, Bensheim, Germany).

\section{Preparation for cementation}

In both groups, the following configurations were used: marginal adhesive gap: $80 \mu \mathrm{m}$ and margin thickness: $0 \mu \mathrm{m}$. Table 1 presents the comparison between the two groups. Each specimen was seated and gently pressed against its respective pillar without prior adjustment. A light addition silicone (Virtual Ivoclar Vivadent, Liechtenstein) was placed

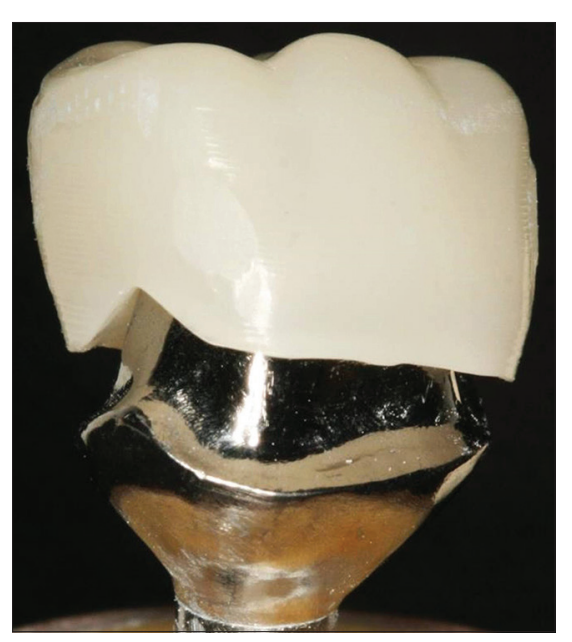

Figure 1: Cemented abutment designed for the study and feldspathic porcelain crown 
inside each specimen with the use of a specific mixing tip. With the purpose of standardizing the force applied to the ceramic parts, a metallic device was used with a fixed base, where the pillar and its respective specimen were positioned, and a mobile base, to which a force of $50 \mathrm{~N}$ was applied, ${ }^{[9]}$ directed at exactly the center of the ceramic crown. Next, the waiting time indicated by the manufacturer was respected.

\section{Analysis of vertical adaptation}

With the support of a stereomicroscope (Olympus SZX9, Japan) coupled to a computer, the microscopic analysis of the abutment interface and the feldspathic crown using the $42.5 x$ objective lens. Using the software ISCapture version 3.7.8 (Xintu, China), the specimens were measured and 6 points of each hexagonal ring were standardly selected for measurement. At each measurement point, three measurements of the prosthetic interface were made [Figure 2], a total of 18 measurements per specimen. The limit considered for the measurement of the vertical microgap was the limit of the abutment at the edge of the feldspathic crown.

\section{Statistical analysis}

The analysis of the quantitative data obtained was organized in Excel spreadsheets (Microsoft Office Excel, United States) with the means and was tested for distribution of normality (Shapiro-Wilk) and variance (Brown-Forsythe). Therefore, $t$-test was used to analyze the comparison factor between the groups

\begin{tabular}{|c|c|c|}
\hline \multicolumn{3}{|c|}{ Comparison between the open system and the closed system } \\
\hline Items & Open system & CEREC \\
\hline Infrastructure & Identical & Identical \\
\hline Blasting & Titanium dioxide & Titanium dioxide \\
\hline Scanner & $\begin{array}{l}\text { Optimet scanner } \\
\text { DS } 6000\end{array}$ & $\begin{array}{l}\text { CEREC scanner } \\
\text { 3D Bluecam }\end{array}$ \\
\hline CAD software & Exocad & CEREC SW 4.2.4 \\
\hline $\begin{array}{l}\text { Marginal } \\
\text { adhesive gap }\end{array}$ & $80 \mu \mathrm{m}$ & $80 \mu \mathrm{m}$ \\
\hline Margin thickness & $0 \mu \mathrm{m}$ & $0 \mu \mathrm{m}$ \\
\hline Crown material & Feldspathic porcelain & Feldspathic porcelain \\
\hline Cutters & $\begin{array}{l}\text { Cylindrical } 1.1 / \\
\text { straight top } 1.1\end{array}$ & $\begin{array}{l}\text { Cylindrical } 12 \mathrm{~s} / \\
\text { straight top } 12 \mathrm{~s}\end{array}$ \\
\hline Milling machine & DM5 - tecnodrill & $\begin{array}{l}\text { InLab MC } \\
\text { XL - CEREC }\end{array}$ \\
\hline Cementing agent & Light addition silicone & Light addition silicone \\
\hline $\begin{array}{l}\text { Force applied in } \\
\text { cementation }\end{array}$ & $50 \mathrm{~N}$ & $50 \mathrm{~N}$ \\
\hline
\end{tabular}

and their respective crown analysis regions $(1,2,3,4$, 5 , and 6 ) between the groups. For the comparison of the variance of the crown analysis regions within the group, one-way ANOVA test was used. The statistics software used was SigmaPlot 13.0 (SPSS Inc., Chicago, IL, USA), and a significance level of $5 \%$ was considered for the analyses.

\section{RESULTS}

In data analysis, a significant difference was observed in the comparison of the CS group $(23.75 \pm 3.05)$ with the OS group (17.94 $\mu \mathrm{m} \pm 4.77), P=0.007$, and the CS group presented the highest mean of marginal discrepancy [Figure 3]. In a dispersion graphic [Figure 4], there are similar points between the groups and the analogous tendency line, with the presence of the smallest points in the OS group and highest points in the CS group.

In the comparison between the six locations assessed in the study groups, a significant difference was observed only in region $1(P=0.012)$ corresponding to vestibular and region $4(P=0,016)$, corresponding to lingual. The highest discrepancy levels were found in the CS group [Table 2].

There was no significant difference between the different crown regions analyzed $(1,2,3,4,5$, and 6) within the two groups, $P \geq 0.05$, demonstrating uniformity in the cervical finish line in both groups, as seen in Table 2.

\section{DISCUSSION}

The study sought to compare the marginal adaptation of crowns using two different CAD/CAM

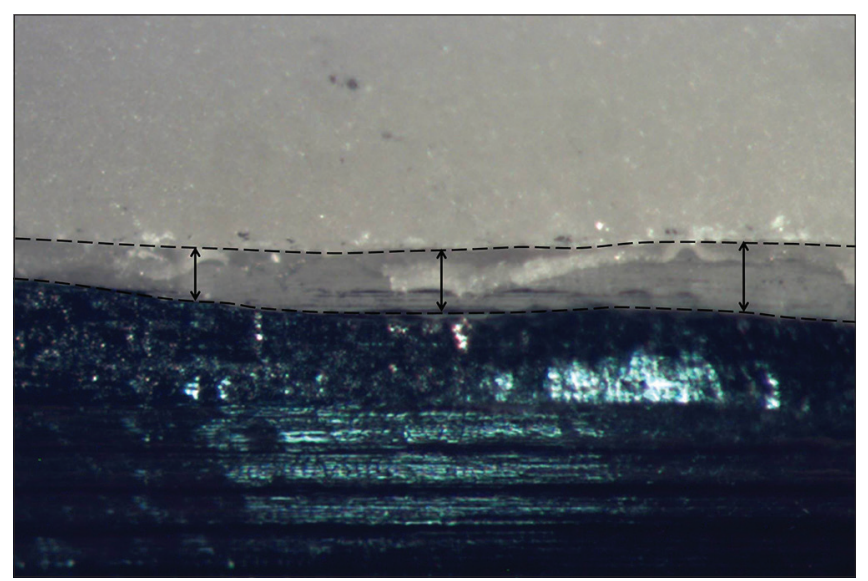

Figure 2: Photomicroscopy $42.5 \times$ demonstrating the reading of the three points of the vertical microgap 


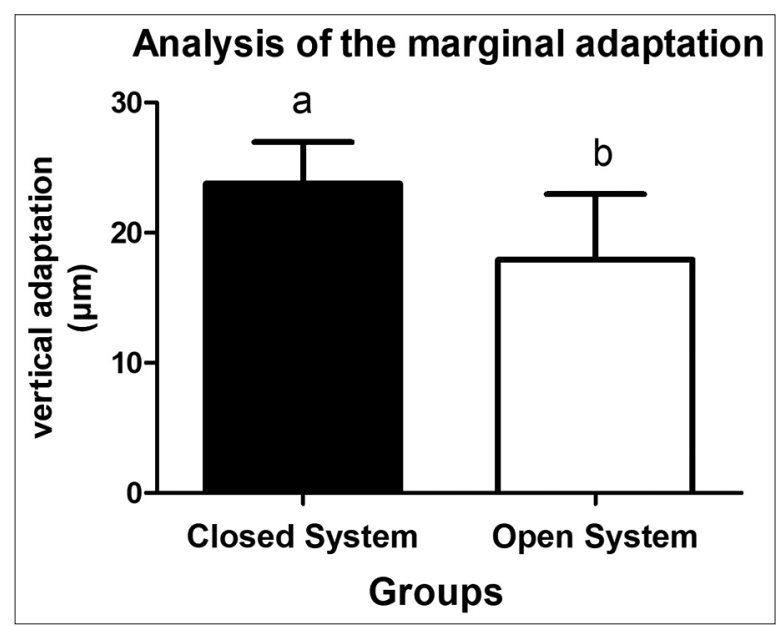

Figure 3: Cemented abutment designed for the study and feldspathic porcelain crown

manufacturing systems: an OS, employing software and equipment of varied brands, and an another one named CS, in which the whole process was conducted using software and equipment from a same manufacturer (CEREC). The analysis of marginal adaptation of the crowns showed lower vertical discrepancy in the group that used the OS. In a second analysis of the data, we observed a significant difference between two regions ( 1 and 4 ) measured between the groups, refusing the null hypothesis of no significant difference when using these two systems. However, both groups reached low levels of vertical discrepancy, similar tendency line and no difference significant misfit within groups (uniformity in the cervical finish line), demonstrating that both systems have positive results and can be used clinically.

The parameter that is most widely used in vitro and is well accepted in the literature for the verification of prosthetic component adaptation is the analysis of marginal adaptation, using the optical microscope. ${ }^{[10]}$ In this sense, several authors have proposed values that would be acceptable for marginal adaptation. However, there is no consensus on such values, rendering them controversial. A classical study reports that the clinical limit would be up to $120 \mu \mathrm{m} .{ }^{[11]}$ More current studies have shown that CAD/CAM systems are achieving results below $80 \mu \mathrm{m}^{[12]}$ corroborating with the results found in this study. However, in addition to the averages, it is necessary to interpret the uniformity of all the adaptation points analyzed, since only with the average, there can be false positives. In this study, the uniformity between all points measured in the two groups was observed, which shows uniformity in the cervical finishing line in both groups.

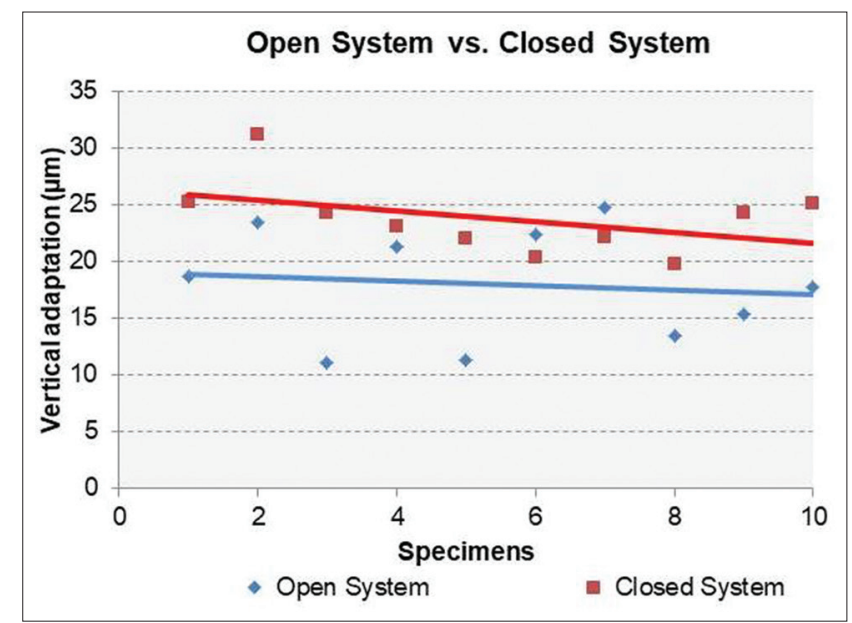

Figure 4: Dispersion graphic with tendency line between groups

\begin{tabular}{|c|c|c|}
\hline \multirow[t]{2}{*}{ Region } & \multicolumn{2}{|c|}{ Mean $(\mu \mathrm{m}) \pm \mathrm{SD}$} \\
\hline & Open system & Closed system \\
\hline 1 & $16.15 \pm 6.75^{\mathrm{A}}$ & $24.51 \pm 6.55^{\mathrm{B}}$ \\
\hline 2 & $17.30 \pm 6.38^{a}$ & $23.56 \pm 9.04^{b}$ \\
\hline 3 & $18.75 \pm 10.01^{a}$ & $24.20 \pm 11.55^{b}$ \\
\hline 4 & $17.62 \pm 5.96^{A}$ & $26.07 \pm 8.11^{\mathrm{B}}$ \\
\hline 5 & $17.73 \pm 4.78^{\mathrm{a}}$ & $23.13 \pm 7.54^{b}$ \\
\hline 6 & $20.15 \pm 5.34^{a}$ & $22.95 \pm 4.26^{b}$ \\
\hline
\end{tabular}

*Different uppercase letters indicate significant differences, $P<0.05$ (A, B). Equal letters $(A, a ; B, b)$ or different lowercase letters $(a, b)$ indicate that there was no significant difference, $P \geq 0.05$. SD: Standard deviation

Considering the above is reported that four pillars are essential for the marginal adaptation in crowns manufactured in CAD/CAM systems. ${ }^{[13]}$ Among them is the definition of the cervical preparation terminus line, which is subject to the operator is interpretation. Because, it is possible to manipulate the finishing line configuration; thus, the operator is experienced and care is doubtlessly relevant for the results. This study used the same experienced operator for both groups. Moreover, cement space, cementation, and crown manufacturing procedure are also considered essential. These were controlled variables in our study controlled because the methodology was identical and was not subject to manipulation or interpretation, unlike the definition of the preparation finish line. In addition, only one calibrated examiner performed the analysis of vertical adaptation of the crowns.

Several studies have compared closed CAD/CAM systems, ${ }^{[1,5,6,14]}$ but the comparison between a closed manufacturing system and an OS is scarce. This is one of the first studies that use this methodology, 
evaluating only the differences between CAD/ CAM systems. Because, the same configuration was used for crown construction, molding and cementation in both groups. The research shows that systems that allow the choice of different software, scanners, and milling machines may present positive results.

The milling machine used in this study for the OS group has 5 axes, unlike the CEREC milling machine of 4 axes. This could be connected to a better finishing in the cervical region of the restoration and may impact on marginal adaptation. Nevertheless, in a recent research, the comparison between onlay restorations with CAD/CAM systems showed no difference in marginal adaptation when milling machines of 3 and 5 axes were compared. On the other hand, the 5-axis milling machine showed superior performance in internal adaptation. ${ }^{[15]}$ The literature, for example, shows that a simple version change of the CAD drawing software significantly interferes in the marginal adaptation of crowns and in the applicability of cement space. ${ }^{[16]}$ This study suggests that even using identical parameters in the studied groups, there may be intrinsic parameter differences between the drawing software used.

It would be, therefore, interesting for future studies to carry out comparative studies of different systems, software, and different types of materials, adding the internal adaptation analysis (micro-CT), which was a methodological limitation of our study, where we would analyze the passivity of the crown. In addition, the incorporation of new three-dimensional analyzes, such as the finite element method ${ }^{[17,18]}$ and the analysis of the marginal adaptation in all its extension, ${ }^{[19]}$ not only by points, would be interesting. Especially, comparing closed CAD/CAM systems with different types of OSs, to generate more knowledge about these systems, their compatibility and prosthesis adaptation potential.

\section{CONCLUSIONS}

Within the limitations of the present in vitro study, it can be concluded:

1. The marginal adaptation of the crowns manufactured with two CAD/CAM systems was better in the group that used the OS

2. The two groups demonstrating uniformity in the cervical finish line in all regions studied

3. Both studied groups achieved clinically acceptable results within the standards established in the literature, suggesting that OSs standardized as CSs can be used clinically.

\section{Financial support and sponsorship}

This study was financially supported by grant number 15/14741-8 from the SAO Paulo Research Foundation (FAPESP).

\section{Conflicts of interest}

There are no conflicts of interest

\section{REFERENCES}

1. Schönberger J, Erdelt KJ, Bäumer D, Beuer F. Marginal and internal fit of posterior three-unit fixed zirconia dental prostheses fabricated with two different CAD/CAM systems and materials. Clin Oral Investig 2017;21:2629-35.

2. Lins L, Bemfica V, Queiroz C, Canabarro A. In vitro evaluation of the internal and marginal misfit of CAD/CAM zirconia copings. J Prosthet Dent 2015;113:205-11.

3. Abduo J, Bennani V, Waddell N, Lyons K, Swain M. Assessing the fit of implant fixed prostheses: A critical review. Int J Oral Maxillofac Implants 2010;25:506-15.

4. Real-Voltas F, Romano-Cardozo E, Figueras-Alvarez O, Brufau-de Barbera M, Cabratosa-Termes J. Comparison of the marginal fit of cobalt-chromium metal-ceramic crowns fabricated by CAD/CAM techniques and conventional methods at three production stages. Int J Prosthodont 2017;30:304-5.

5. Neves FD, Prado CJ, Prudente MS, Carneiro TA, Zancopé K, Davi LR, et al. Micro-computed tomography evaluation of marginal fit of lithium disilicate crowns fabricated by using chairside CAD/CAM systems or the heat-pressing technique. J Prosthet Dent 2014;112:1134-40.

6. Renne W, Wolf B, Kessler R, McPherson K, Mennito AS. Evaluation of the marginal fit of CAD/CAM crowns fabricated using two different chairside CAD/CAM systems on preparations of varying quality. J Esthet Restor Dent 2015;27:194-202.

7. Ha SJ, Cho JH. Comparison of the fit accuracy of zirconia-based prostheses generated by two CAD/CAM systems. J Adv Prosthodont 2016;8:439-48.

8. Guess PC, Zavanelli RA, Silva NR, Bonfante EA, Coelho PG, Thompson VP, et al. Monolithic CAD/CAM lithium disilicate versus veneered Y-TZP crowns: Comparison of failure modes and reliability after fatigue. Int J Prosthodont 2010;23:434-42.

9. Beuer F, Edelhoff D, Gernet W, Naumann M. Effect of preparation angles on the precision of zirconia crown copings fabricated by CAD/CAM system. Dent Mater J 2008;27:814-20.

10. Torabi K, Vojdani M, Giti R, Taghva M, Pardis S. The effect of various veneering techniques on the marginal fit of zirconia copings. J Adv Prosthodont 2015;7:233-9.

11. McLean JW, von Fraunhofer JA. The estimation of cement film thickness by an in vivo technique. Br Dent J 1971;131:107-11.

12. Boitelle P, Mawussi B, Tapie L, Fromentin O. A systematic review of CAD/CAM fit restoration evaluations. J Oral Rehabil 2014;41:853-74.

13. Contrepois M, Soenen A, Bartala M, Laviole O. Marginal adaptation of ceramic crowns: A systematic review. J Prosthet Dent 2013;110:447-540000000000.

14. Memarian M, Sadighpour L, Nosratpour R, Fard MJ. Marginal adaptation and internal fit of posterior 3-unit zirconia FPDs fabricated with different CAD/CAM systems. Eur J Prosthodont Restor Dent 2017;25:79-85.

15. Alajaji NK, Bardwell D, Finkelman M, Ali A. Micro-CT evaluation of ceramic inlays: Comparison of the marginal and internal fit of five and three axis CAM systems with a heat press technique. J Esthet Restor Dent 2017;29:49-58.

16. Shim JS, Lee JS, Lee JY, Choi YJ, Shin SW, Ryu JJ, et al. Effect of software version and parameter settings on the marginal and internal adaptation of crowns fabricated with the CAD/CAM system. J Appl Oral Sci 2015;23:515-22. 
Kricheldorf, et al.: Analysis of the adaptation crowns with CAD/CAM systems

17. Bramanti E, Cervino G, Lauritano F, Fiorillo L, D'Amico C, Sambataro S, et al. FEM and von mises analysis on prosthetic crowns structural elements: Evaluation of different applied materials. ScientificWorldJournal 2017;2017:1029574.

18. Cicciù M, Cervino G, Bramanti E, Lauritano F, Lo Gudice G, Scappaticci L, et al. FEM analysis of mandibular prosthetic overdenture supported by dental implants: Evaluation of different retention methods. Comput Math Methods Med 2015;2015:943839.

19. Al-Meraikhi H, Yilmaz B, McGlumphy E, Brantley W, Johnston WM In vitro fit of CAD-CAM complete arch screw-retained titanium and zirconia implant prostheses fabricated on 4 implants. J Prosthet Dent 2017; pii: S0022-3913 (17) 30311-6. 